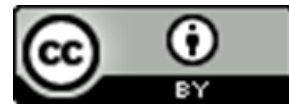

\title{
A CONSTRUÇÃO E APAGAMENTO DE TERRITÓRIOS NEGROS
}

\author{
Azânia Mahin Romão Nogueiral
}

Resumo: Apontar os processos de construção e apagamento de territórios negros a partir das disputas existentes no Centro de Florianópolis, capital de Santa Catarina, foi o fio condutor para a escrita deste artigo. Compreendendo que os territórios negros são expressões espaciais que geografam as relações raciais, apresento a lógica de ocupação e organização da população negra no município. Além de assinalar o constante esforço de branqueamento do bairro a partir de seu ordenamento espacial e controle dos corposterritórios, também está presente a resistência da população negra, organizada ou não, na ocupação de seu território e defesa de seus marcadores simbólicos, como a Escola Antonieta de Barros. Saliento o papel da Geografia na legitimação da desracialização territorial em curso e a necessidade de retomada da raça enquanto categoria analítica no discurso hegemônico da Geografia brasileira.

Palavras-chave: territórios negros; relações raciais; relações de poder.

\section{THE CONSTRUCTION AND ERASURE OF BLACK TERRITORIES}

Abstract: Pointing out the processes of construction and erasure of black territories from the disputes existing in Downtown Florianópolis, capital of Santa Catarina, was the guiding thread for the writing of this article. Understanding that black territories are spatial expressions that geograph racial relations, I present the logic of occupation and organization of the black population in the municipality. In addition to pointing out the constant effort to whiten the neighborhood based on its spatial ordering and control of the bodies-territories, there is also the resistance of the black population, organized or not, in the occupation of its territory and defense of its symbolic markers, such as the Antonieta de Barros School. I emphasize the role of Geography in legitimizing ongoing territorial de-racialization and the need to retake race as an analytical category in the hegemonic discourse of Brazilian Geography.

Keywords: black territories; race relations; power relations.

\section{LA CONSTRUCCIÓN Y EL BORRADO DE LOS TERRITORIOS NEGROS}

Resumen: Señalar los procesos de construcción y eliminación de territorios negros de las disputas existentes en el centro de Florianópolis, capital de Santa Catarina, fue el hilo conductor para la redacción de este artículo. Comprendiendo que los territorios

\footnotetext{
${ }^{1}$ Mestre em Geografia UFSC. E-mail: azania.mahin@gmail.com ; ORCID: https://orcid.org/0000-0001$\underline{6637-9883}$
} 
negros son expresiones espaciales que geografían las relaciones raciales, presento la lógica de ocupación y organización de la población negra en el municipio. Además de señalar el esfuerzo constante para blanquear el vecindario basado en su ordenamiento espacial y el control de los cuerpos-territorios, también existe la resistencia de la población negra, organizada o no, en la ocupación de su territorio y la defensa de su marcadores simbólicos, como la escuela Antonieta de Barros. Enfatizo el papel de la Geografía en la legitimación de la des racialización territorial en curso y la necesidad de retomar la raza como categoría analítica en el discurso hegemónico de la Geografía brasileña.

Palabras llave: territorios negros; relaciones raciales; relaciones de poder.

\section{LA CONSTRUCTION ET L'EFFACEMENT DES TERRITOIRES NOIRS}

Résumé: Soulignant les processus de construction et d'effacement des territoires noirs des conflits existant au centre-ville de Florianópolis, capitale de Santa Catarina, a été le fil conducteur de la rédaction de cet article. Comprenant que les territoires noirs sont des expressions spatiales qui géographient les relations raciales, je présente la logique d'occupation et d'organisation de la population noire dans la commune. En plus de souligner l'effort constant de blanchiment du quartier basé sur son ordonnancement spatial et le contrôle des corps-territoires, il y a aussi la résistance de la population noire, organisée ou non, à l'occupation de son territoire et à la défense de sa symbolique marqueurs, comme l'école Antonieta de Barros. J'insiste sur le rôle de la géographie dans la légitimation de la racialisation territoriale en cours et sur la nécessité de reprendre la race comme catégorie analytique dans le discours hégémonique de la géographie brésilienne.

Mots-clés: territoires noirs; relations raciales; relations de pouvoir.

\section{INTRODUÇÃO}

Mais do que uma categoria analítica importante para o conhecimento geográfico, os territórios negros materializam acúmulos de diferentes momentos históricos da resistência negra frente à colonização, higienização e gentrificação do espaço. Não há dúvida no papel da classe social na distribuição da população negra no espaço, mas é indispensável a discussão a partir da raça para compreender a permanência dessa população nestes espaços, visto que o reconhecimento da existência de desigualdades raciais não alterou a situação da população negra que continua ocupando lugares subalternizados na sociedade brasileira.

Compreendo território enquanto "um espaço definido e delimitado por e a partir de relações de poder" (SOUZA, 2011, p. 78). As relações raciais, por sua vez, são fundamentalmente relações de poder que se materializam a partir da hierarquização das 
raças e etnias. O racismo é, portanto, uma forma de exercício de poder de um grupo sobre outro. Nesse sentido, ao apresentar os processos de construção e apagamento de territórios negros a partir das disputas existentes no Centro de Florianópolis, capital de Santa Catarina, denuncio o racismo existente no constante esforço de branqueamento da cidade a partir de seu ordenamento espacial e controle dos corpos-territórios negros. Em contrapartida, também está apresento a resistência da população negra, seja ela organizada ou não, na ocupação de Florianópolis e na defesa de seus marcadores simbólicos no município, como a Escola Antonieta de Barros.

Considerando que os territórios negros são expressões espaciais que geografam as relações raciais e essas relações têm formas diversas de se expressar na sociedade no mundo todo, é com a mesma multiplicidade que os territórios negros se apresentam. No Brasil, de forma generalizada, as relações raciais ainda estão calcadas no mito da democracia racial, apesar das alegações de superação do mesmo, onde as "três raças" vivem em aparente harmonia. Na realidade, a construção social de raça classifica e hierarquiza todos os que aqui vivem, a partir de diversos aspectos, sendo o fenótipo um deles. Ainda assim, territórios exclusivamente compostos por pessoas negras são raros no país, especialmente considerando que outros fatores, como a segregação social, também geografam o espaço. Nesse sentido, Alex Ratts afirma que territórios negros são espaços "apropriados, marcados, qualificados por grupos negros, ainda que não sejam exclusivos” (RATTS, 2012, p. 232), sendo essa demarcação materializada a partir da presença de "um conjunto de códigos e símbolos compartilhados, enfim, um modo de vida" (RATTS, 2004, p. 85). Com isso, são múltiplos elementos que caracterizam o que aqui chamamos de territórios negros, fatos espaciais definidos a partir de relações de poder focadas na perspectiva racial, onde a identidade negra se faz presente, seja pela autodeclaração daqueles que se apropriam daquele espaço, seja pela presença de “marcadores culturais e simbólicos" (BENEDITO, 2013, p. 99). Esses marcadores podem ser organizações sociais, como coletivos e organizações do Movimento Negro; culturais, como escolas de samba, grupos de capoeira, clubes negros, bailes de música black e funk, rodas de samba e pagode; religiosas, como irmandades negras e terreiros de religiões de matriz africana; políticas, que vão desde atuação de partidos, como a Frente Negra, na década de 1950, até a posição de poder dentro desses territórios 
ocupados por negros, como líderes religiosos, políticos, moradoras/es antigas/os ou de maior prestígio social, comerciantes, professoras, benzedeiras e parteiras.

Os territórios negros diferenciam-se pela resistência coletiva à colonialidade, engajada ou não, por isso, é possível falar de territórios negros mesmo em espaços onde a população é majoritariamente negra, como no Brasil, pois não se trata de um processo de formar guetos em espaços brancos, mas do reconhecimento da multiplicidade do espaço e das relações raciais enquanto relações de poder. Tendo enquanto precedente que estas relações são organizadas por um sistema que impacta cada um de nós, os corpos negros que territorializam o espaço também são territorializados, a medida em que para o controle do território por parte do Estado e do mercado, busca-se o controle dos corpos. Nesse sentido, o corpo é o primeiro território a ser dominado e o primeiro território a resistir frente ao controle do poder hegemônico. Dessa forma, é essencial considerar o corpo nas categorias analíticas quando estamos falando de qualquer aspecto da sociedade.

A intenção com este artigo não é fazer um "recorte" ou apontar a presença negra como dissociada da identidade nacional, considerando que a população negra é majoritária no Brasil, como apontado pelo Censo Demográfico de 2010, dessa forma, ele próprio pode ser considerado um território negro, mas perceber como as relações raciais se apresentam na formação socioespacial brasileira, especialmente em Florianópolis. Com ele, pretendo também avançar em lacunas presentes em minha dissertação de mestrado, onde, além de abordar a construção conceitual e espacial de territórios negros, espacializei a presença negra em Florianópolis, tendo os bairros como lócus e os identificando enquanto territórios negros no município. Aqui, busco aprofundar a ideia de multiplicidade identitária de um território, compreendendo que este possui uma identidade própria, mas que não única, de forma que um mesmo marcador pode compartilhar diferentes sentidos para grupos distintos. Com isso, quero demonstrar que a particularidade de cada lugar vai além da sua história, construindo-se a partir das relações sociais que "se encontram e se entrelaçam num lócus particular" (MASSEY, 2000, p. 184). Portanto, quando aponto a existências de territórios negros e seus marcadores, não pretendo dizer que estes são exclusivamente negros. Também não é meu objetivo reforçar uma dicotomia entre territórios negros e não negros, considerando a abrangência da população negra no município de Florianópolis, mas sim 
visibilizar a existência de territórios de resistência dessa população frente aos processos de colonialidade ainda presentes na sociedade.

Antonia dos Santos Garcia (2009) aponta o "paradoxo contemporâneo brasileiro" onde se reconhece a existência do racismo, mas não da existência de mecanismos sociais que perpetuam as desigualdades raciais. A partir das disputas atualmente travadas sobre a Escola Antonieta de Barros, no Centro de Florianópolis, pretendo também apontar o funcionamento destes mecanismos e como a Geografia contribui para sua manutenção.

\section{A GEOGRAFIA DAS RELAÇÕES RACIAIS}

Diogo Marçal Cirqueira (2015), ao investigar as inscrições da racialidade no pensamento geográfico entre 1880 e 1930, aponta a presença da raça como conceito analítico na Geografia desde sua formação moderno-colonial, quando as leituras racializadas eram incorporadas às discussões de espaço. Cirqueira também aponta que

(...) a fetichização da classe pelos geógrafos críticos conduziu ao sequestro das outras categorias de diferença (que não fossem a de classe) e a conformação de uma amnésia na disciplina acerca dos debates sobre etnia e raça - do mesmo modo, gênero (CIRQUEIRA, 2015, p. 28).

Mais do que uma amnésia, a ausência de outras categorias além da classe se dá por escolhas epistemológicas, portanto, políticas. Deste modo, é urgente retomar o debate no discurso acadêmico geográfico hegemônico que considera a raça conceito analítico da Geografia e variável da desigualdade socioespacial, considerando a tarefa histórica de superação da hierarquização racial enquanto forma de organização da sociedade e o papel do conhecimento científico socialmente referenciado na compreensão e naturalização das dinâmicas sociais. A escolha de não utilizar a raça como conceito analítico reforça uma "desracialização" das relações sociais brasileiras, reforçando assim o mito da democracia racial. Ainda, é fundamental compreender que essa categoria de análise existe porque essa população existe. Assim, a omissão com relação a este debate é também a negação da espacialidade dessa população.

Da mesma forma que quilombos, comunidades indígenas, assentamentos rurais e outros territórios de povos tradicionais se constituem enquanto espaços de resistências, 


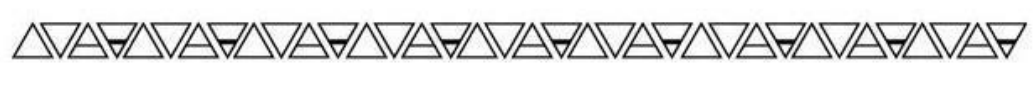

os corpos racializados, das mulheres, da população LGBTQ, de pessoas com deficiência, entre outros, também disputam espaços controlados pelo poder hegemônico. A produção acadêmica, os currículos dos cursos nas instituições de ensino superior, as temáticas dos eventos, as publicações em livros e periódicos, as produções e linhas de pesquisa dos programas de pós-graduação, são alguns dos espaços em que o discurso geográfico se (re)produz. Eles constituem um espaço territorializado a partir de dinâmicas fundamentadas em uma estrutura racista, patriarcal, cisheteronormativa, capacitista e meritocrática. Isso não significa que não existam discursos dissonantes, especialmente neste momento histórico onde corpos marginalizados passam a acessar estes espaços. Assim, como em qualquer espaço de poder, as tensões existem, sendo traduzidas em produções heterogêneas, mas que ainda ocupam um lugar secundarizado no pensamento geográfico.

Milton Santos afirma que cada indivíduo "vale pelo lugar onde está: o seu valor como produtor, consumidor, cidadão, depende de sua localização no território" (SANTOS, 1987, p. 81). Esses lugares ganham valores e, a partir deles, seus habitantes também são valorados. E a raça é um dos fatores que define quais lugares serão prestigiados e quais serão estigmatizados, criando uma relação dialética entre território (espacial, acadêmico, simbólico) e lugar social.

As formas de apropriação dos territórios estão intimamente relacionadas à identidade, visto que se tratando da ocupação humana também é através de nossos corpos que demarcamos o pertencimento à um lugar. Os corpos também materializam a intersecção particular de cada um de nós, que comunicam diferentes acúmulos de experiências interpessoais e em relação ao sistema que organiza e hierarquiza as pessoas. Assim, nossos corpos e nossas identidades também são territórios em disputa.

Muniz Sodré, ao discorrer sobre o "corpo-território" afirma que

todo individuo percebe o mundo e suas coisas a partir de si mesmo, de um campo que lhe é próprio e que se resume em última instância, a seu corpo. O corpo é lugar zero do campo perceptivo, é um limite a partir do que se define um outro, seja coisa ou pessoa. O corpo serve-nos de bússola, meio de orientação com referência aos outros (SODRÉ, 1988, p. 123).

É a partir do controle dos corpos-territórios que o Estado mantém a ordem espacial burguesa que é uma das formas pelas quais o sistema capitalista se reproduz. 
Considerando o que aqui foi exposto, na ordem espacial burguesa vigente no país os territórios negros são, concomitantemente, espaços de resistência e de controle de corpos. A partir do controle que o Estado impede a mobilidade das pessoas pelo espaço, por diversos aparatos, desde as condições de transporte público ao uso das forças de "segurança pública". A forma de controle dos corpos tem total ligação com o território que ocupam ou que são designadas para que ocupem, tornando inseparável a condição de corpo-território (MONDARDO, 2009).

Partiremos desta compreensão para pensar nas dinâmicas de demarcação e apagamento em um território negro em Florianópolis, Santa Catarina. Para isso, a seguir apresentarei a lógica de ocupação e organização da população negra no município para uma breve contextualização de suas dinâmicas raciais.

\section{TERRITÓRIOS NEGROS EM FLORIANÓPOLIS: UMA BREVE CONTEXTUALIZAÇÃO}

No município de Florianópolis, capital de Santa Catarina, o estado com menor proporção de negros $(15,35 \%)$ no país, $14,69 \%$ da população de 421.240 habitantes se declara como negra.

O regime escravocrata teve papel fundamental na distribuição geográfica da população negra no Brasil e, diferentemente do que o senso comum pode acreditar, desde a primeira fase da ocupação europeia do litoral catarinense, no século XVII, houve o emprego da mão de obra escravizada, tanto indígena quanto afrodescendente. Entre 1746 e 1796, foram fundadas cinco armações baleeiras no litoral catarinense, estas sendo unidades escravistas de porte comparável a engenhos de cana e fazendas de café. Esta informação, somada aos dados da Intendência de Polícia da Corte do Rio de Janeiro, de que entre 1811 e 1830 chegaram a cerca de 1.700 os trabalhadores escravizados em Santa Catarina, apontam que a realidade econômica rural do estado diverge do que classificaram os historiadores Walter Piazza e Oswaldo Cabral, que consideravam os minifúndios catarinenses com baixo trabalho escravo (CARDOSO; MAMIGONIAN, 2013).

A população negra em Florianópolis no século XIX, quando a cidade ainda se chamava Nossa Senhora de Desterro, não constituía um grupo homogêneo, sendo 
composta por pessoas em diferentes categorias sociais (escravizadas, libertas ou nascidas livres) e de diferentes origens (africanas ou afrobrasileiras), que, por estarem envolvidas/os nas mais diversas tarefas, circulavam por diversas partes da cidade, em todos os horários do dia, estabelecendo também relações entre si. O bairro da Figueira, composto em sua maioria por essa população, era um dos territórios ocupados pela população negra e pobre, juntamente com os bairros da Tronqueira e da Pedreira (MORTARI; DEBORTOLI, 2014).

Nesse momento, pela ordem espacial burguesa vigente em Desterro, haviam duas fronteiras de raça não declaradas traçadas na cidade: uma situada nas adjacências da atual rua Conselheiro Mafra e outra nas adjacências da atual avenida Hercílio Luz, onde na época corria livre o rio da Bulha. O controle dos corpos-territórios negros na época se dava especialmente a partir dos Códigos de Posturas que "visavam regulamentar e controlar suas condutas e formas de expressão culturais de africanos e seus descendentes, bem como restringir também a mobilidade desses trabalhadores em determinados horários e espaços da cidade" (MORTARI; DEBORTOLI, 2014, p. 05).

Já no século XX, o movimento sanitarista de Florianópolis passa a atuar em diferentes frentes para a validação de suas práticas higienistas. A produção de conhecimento em periódicos endossava as políticas públicas postas em prática, como inspeções sanitárias domiciliares e reformas urbanas. O ponto culminante deste movimento se dá com o início da construção da avenida Hercílio Luz, a primeira da cidade (AREND, 2005). Para a construção da avenida, foram extintos os bairros da Toca e da Tronqueira, território das populações pobres e negras e o rio da Bulha fora canalizado. A canalização do rio bem como a associação da atividade das lavadeiras a algo insalubre para a população fez com que as lavadeiras, muitas delas trabalhadoras negras, deixassem de ser figuras onipresentes da cidade para subirem as encostas do Morro do Antão, hoje conhecido como Morro da Cruz. Quanto a esse processo de expulsão das populações do centro, Elaine Veras da Veiga afirma que

Os problemas habitacionais decorrentes dessa pressão acentuaram o processo degenerativo de algumas ruas do centro urbano, tornando insustentável a permanência de cortiços, como os do beco Sujo, beco Irmão Joaquim, rua São Martinho e outros. O saneamento e urbanização da avenida Hercílio Luz, nas imediações da qual muitos deles se instalaram, parece ter expulsado parte da população humilde, que ou passou a instalar favelas no sopé dos morros da 
cidade, ou conquistou um novo patamar na escala de habitações, organizando-se em vilas (VEIGA, 2008, p. 110).

Com a saída da população pobre, a avenida Hercílio Luz tornou-se "uma das regiões residenciais prediletas da classe média e ali se multiplicaram habitações de fachadas ecléticas, dotadas de conforto e padrões higiênicos sadios" (VEIGA, 2008, p. 215). Assim, a avenida Hercílio já nasce enquanto materialização da fronteira de cor no Centro decorrente do movimento higienista que expulsou a população negra das regiões centrais da cidade.

Nessa época, se intensifica a ocupação do Maciço do Morro da Cruz, onde hoje a prefeitura estima que vivem 22.566 habitantes em 16 comunidades: Mariquinha, Rua Ângelo Laporta, Monte Serrat, Rua José Boiteux, Tico Tico, Rua Laudelina da Cruz, Morro do 25, Vila Santa Vitória, Morro do Horácio, Vila Santa Clara, Morro da Penitenciária, Serrinha, Morro da Queimada e Jagatá, Alto da Caeira, Morro do Céu e Mocotó. O Maciço, com mais de $657 \mathrm{mil} \mathrm{km}^{2}$, pelos dados oficiais acaba dividido em vários bairros, já que os limites definidos pela cartografia oficial não levam em consideração a composição e extensão deste território que origina-se da expulsão dos pobres, em sua maioria negros, da região central da cidade (FLORIANÓPOLIS, 2018).

Em minha pesquisa de mestrado, tinha como objetivo compreender onde estavam os territórios negros em Florianópolis, tendo os bairros do município como lócus. Como resultados, percebi que a população negra está mais presente no Distrito Sede, o com o maior contingente populacional do município, que abriga os bairros centrais e toda a área continental de Florianópolis, com destaque ao bairro Monte Cristo, na porção continental, com maior contingente populacional negro absoluto e proporcional e o Centro, na ilha, segundo bairro em contingente populacional absoluto e único bairro onde o número de pessoas autodeclaradas pretas é superior a pardas.

A intenção ao apresentar a ordenação populacional do município é de perceber o papel do fator racial na distribuição dos negros em Florianópolis, sendo isso um reflexo das relações raciais presentes no âmago da sociedade brasileira desde sua formação. Isso não significa um binarismo do município, visto que as relações raciais aqui não se resumem a dois grupos distintos, tampouco vivem em completo isolamento, e sim que, até hoje, as populações racializadas têm acesso a oportunidades de forma diferente que os brancos. 
Isto posto, a seguir irei apresentar, a partir da situação envolvendo a Escola Antonieta de Barros no município de Florianópolis, capital de Santa Catarina, e as disputas presentes no controle dos corpos-territórios negros.

\section{ESCOLA ANTONIETA DE BARROS}

O prédio que até recentemente abrigava a Escola de Educação Básica Antonieta de Barros, localizado na rua Victor Meirelles (mapa 01), no Centro de Florianópolis foi construído na década de 1940, após a expulsão da população negra das adjacências da atual avenida Hercílio Luz. A construção compunha, a partir de 1947, o Instituto de Educação Dias Velho, com uma escada que ligava o prédio que atualmente é Museu da Escola Catarinense e na época abrigava a Escola Normal de formação de professoras, ao prédio da Escola, que funciona como escola de aplicação para as professoras. Antonieta de Barros foi diretora do Instituto entre 1945 e 1951, vindo a falecer em 1952. Com a passagem da professora, o prédio da escola passou a ter o nome dela. Em 1963, o Instituto de Educação Dias Velho foi transferido para a avenida Mauro Ramos, passando a se chamar Instituto Estadual de Educação, onde está em funcionamento até hoje, sendo a maior escola de educação básica do município.

A Escola Antonieta de Barros, por sua vez, funcionou enquanto unidade de ensino da educação básica até 2008, quando foi fechada pelo então governador Luiz Henrique da Silveira (PMDB). A principal justificativa para o fechamento era que o prédio, por falta de manutenção, apresentava problemas estruturais. Desde então, ele nunca foi reformado. 
Mapa 01: Localização da Escola Antonieta de Barros
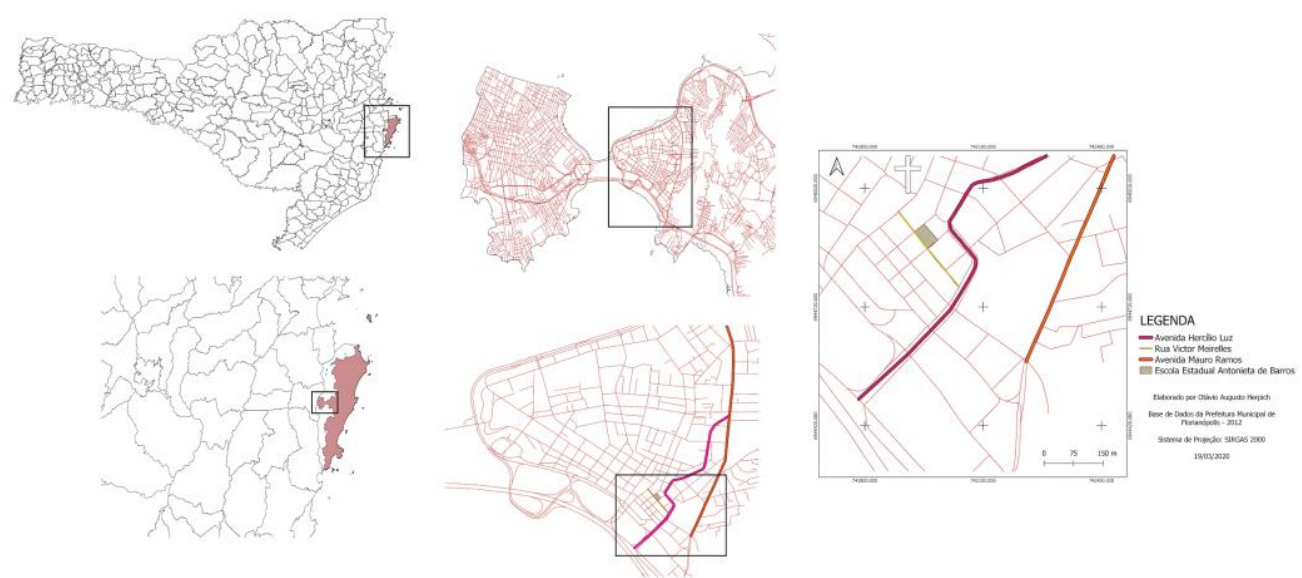

Fonte: Prefeitura Municipal de Florianópolis, 2012

Em minha dissertação (NOGUEIRA, 2018) agrupo os marcadores simbólicos que identificam territórios negros discutidos anteriormente em três grupos gerais, marcadores culturais, socioeconômicos e políticos, e apresento como eles nos possibilitam reconhecer territórios negros a partir do bairro Monte Cristo, também em Florianópolis. Falar de um bairro já se mostrou uma tarefa complexa, especialmente o Monte Cristo e suas particularidades no município, de forma que não consegui articular estas três categorias em uma mesma expressão. Aqui farei esse exercício a partir da Escola Antonieta de Barros, percebendo que esta categorização não foi pensada enquanto uma divisão rígida e singular e sim criada para fins analíticos que, como o método dialético exige na prática, devem ser interseccionalizadas.

\section{MARCADOR CULTURAL}

A cultura tem um papel essencial no processo de apropriação do território e da constituição identitária dos indivíduos. O Movimento Negro, especialmente após a Ditadura militar brasileira (1964 - 1985), tem a cultura como importante vertente de luta política organizada, o que se materializa nas centenas de grupos, coletivos e organizações culturais que se colocam nas inúmeras disputas que as relações raciais desenham no país. 
Um exemplo são as batalhas de rap, espaços de encontro, diálogo e disputa do movimento hip-hop, estão presentes em muitas cidades brasileiras, sendo elas expoentes de artistas do gênero por todo o país.

Falando sobre as batalhas que ocorrem em Florianópolis, Guilherme Filipe Andrade dos Santos afirma que "a cidade está sendo debatida e disputada nas batalhas (...) demonstrando o poder do hip-hop na revolução" (ALÁFIA, 2017, s.p.). O hip-hop, expressão cultural urbana negra, permite perceber a cidade e as relações entre ela e suas/seus protagonistas a partir dos elementos que o compõe, refletindo a vivência destas pessoas. Denílson Araújo de Oliveira (2012) ao discorrer acerca dos territórios demarcados pelos protagonistas do hip-hop no Rio de Janeiro aponta que eles eram apoderados por aqueles provindos de bairros populares e que tensões passaram a existir depois que grupos sociais mais abastados se apropriaram dessa cultura, criando festas elitistas em bairros nobres. O mesmo movimento pode ser observado em Florianópolis, e Yara Tatiane Espíndola, vulgo Berra, relembra que o rap

tem que falar da quebrada, da violência policial e do Estado, das mortes silenciadas, das pessoas que não têm voz, do sistema carcerário... Tem que falar do que é a nossa crise cotidiana, que a gente só disfarça (...) o rap, ele tá aí pra falar de uma parada que é estrutural, que é o racismo, tá ligado? Que mata! (RITMO, 2017).

A antropóloga Angela Maria de Souza (1998; 2016) estudou o movimento hiphop no município e aponta a presença da Geografia no discurso e trajetórias das e dos MCs que aqui vivem. Primeiramente, pela importância do bairro, visto que esses sujeitos falam de e para seu lugar de origem, e do município como um todo. Nas palavras da autora:

se o bairro é uma referência, principalmente, a partir da formação das inúmeras coletividades, a cidade é reivindicada como um direito de todos e não só para os que possuem recurso financeiro para dela usufruir (SOUZA, 2016, p. 183).

Ainda assim, ter o bairro como lócus é importante, visto que, apesar de internamente algumas parcelas da população local não se perceberem como uma unidade territorial, diversas ações, como a aplicação de políticas públicas, abrangem todo o bairro, como observamos na construção da avenida Hercílio Luz. 
Luciana Freitas, intelectual orgânica do movimento negro de Santa Catarina e militante do Movimento Negro Unificado, se refere à Avenida Mauro Ramos, que liga a Baía Sul à Baía Norte da cidade como "a Faixa de Gaza de Florianópolis". A avenida separa o Maciço do Morro da Cruz, território negro autorreferenciado, do restante do bairro. Silvia Arend aponta que construção da avenida, realizada durante o período do Estado Novo, está inserida "no processo de modernização e de implementação dos valores burgueses no espaço urbano de Florianópolis que se inicia nos primórdios do século XX.” (AREND, 2015, p. 144). Para a sua consolidação, mais uma vez houve a expulsão de famílias pobres e negras que já habitavam o pé do Maciço do Morro da Cruz, sendo forçadas a subirem a encosta ou se mudarem para a parte continental da cidade, movimento semelhante ao realizada em outros momentos de ação higienista na parte central de Florianópolis. Se hoje a Mauro Ramos é a fronteira racial do Centro, vimos que no passado foi a avenida Hercílio Luz. O objetivo ao apontar estas fronteiras (mapa 02), também desenhadas a partir das relações de poder, é demonstrar que até hoje a presença negra "do lado de lá" de Florianópolis é empurrada para o "lugar de negro" imposto pela sociedade burguesa a partir das instituições do Estado ao seu serviço, seja pelo controle de seus territórios através de políticas urbanas, seja pelo controle de seus corpos, exercido contemporaneamente especialmente pela Polícia Militar. 
Mapa 02: Fronteiras raciais do Centro de Florianópolis

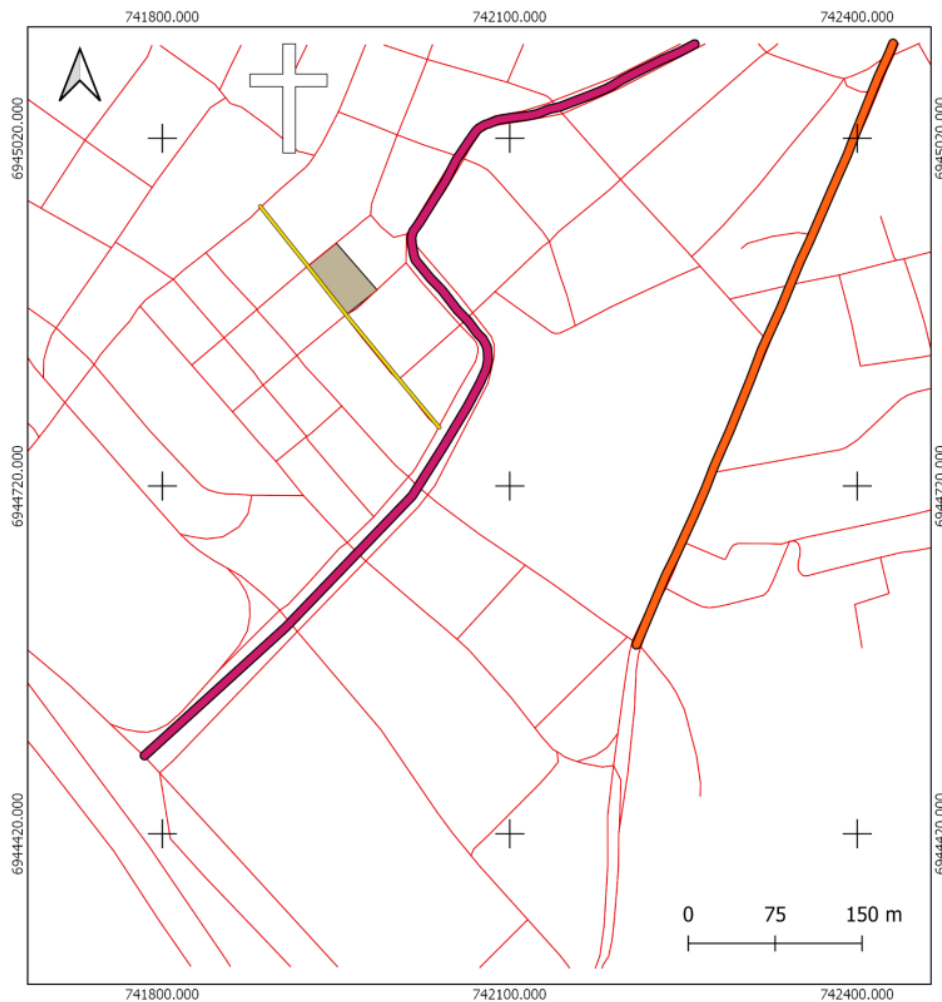

\section{LEGENDA}

$\hookrightarrow$ Avenida Hercílio Luz

— Rua Victor Meirelles

$\Longleftarrow$ Avenida Mauro Ramos

$\square$ Escola Estadual Antonieta de Barros

Elaborado por Otávio Augusto Herpich

Base de Dados da Prefeitura Municipal de Florianópolis - 2012

Sistema de Projeção: SIRGAS 2000

$19 / 03 / 2020$

Fonte: Prefeitura Municipal de Florianópolis, 2012

Um exemplo explícito disso é a forte repressão enfrentada pelas artistas da Batalha das Minas, que já ocupou diferentes locais na cidade para evitar o confronto direto com os funcionários da segurança pública do Estado. Hoje as Minas resistem na Avenida Hercílio Luz, apesar do forte assédio policial durante suas atividades. Com isso, espero deixar explícita as múltiplas formas de embranquecimento de Florianópolis, especialmente no Centro, e também da resistência do povo negro que insiste em ocupar a sua cidade como lhe é direito. Nesse sentido, o prédio da Escola Antonieta de Barros em sua função social originária também se coloca enquanto marcador desta ocupação territorial. Anteriormente frequentada por jovens e crianças negras e da classe trabalhadora, ela demarcava concretamente a trajetória destes corpos no Centro da cidade. A escola, portanto, era um elemento da vida cotidiana das pessoas que habitam este território, especialmente da infância e juventude negra, constituindo a cultura local a partir de suas dinâmicas. 
Além do valor cultural e histórico do prédio reconhecido arquitetonicamente, a escola leva o nome de Antonieta de Barros (1901 - 1952), a primeira deputada estadual mulher do Brasil, única deputada negra do estado de Santa Catarina (1935 - 1937 e 1947 - 1951) e primeira mulher negra a assumir um mandato político no país. Mais do que dar o nome em um prédio, a toponímia da resistência indica o relacionamento de Antonieta com a escola, sua comunidade e o bairro, sendo a mesma moradora do Centro. Além disso, nos dias atuais, mantém viva em nosso cotidiano a deputada, cuja história seria invisibilizada sem os esforços do Movimento Negro local em projetar esta lutadora pelos direitos do povo trabalhador brasileiro.

\section{MARCADOR SOCIOECONÔMICO}

Considerando a cultura, a economia e a política como dimensões socioespaciais, também constituídas pelas relações de poder, penso nos marcadores socioeconômicos como aqueles que nos ajudam a perceber as condições materiais históricas indicadas a partir do acesso à direitos básicos e uma vida digna à população negra.

No âmbito acadêmico e até mesmo governamental, existe um consenso acerca a disparidade de "qualidade de vida" entre brancos e não brancos no Brasil. Em minha pesquisa de mestrado, analisando dados do Monte Cristo, bairro com o maior contingente populacional negro de Florianópolis, ficou evidente a disparidade de acesso à educação e outros serviços especialmente entre as crianças negras que ali vivem e a média municipal. Porém, o uso desses indicadores não tem como objetivo contribuir com a estigmatização dos territórios negros como comunidades carentes, apontando apenas as suas ausências, mas, sim, denunciar a violência estrutural e sistêmica que existe para garantir a manutenção das desigualdades sociais, através da "opressão de grupos, classes, nações e indivíduos, aos quais são negadas conquistas da sociedade" (MINAYO, 1993, p. 08), não aceitando uma interpretação determinista desses territórios.

Considerando que a centralidade deste artigo está na Escola Antonieta de Barros, focalizarei no acesso à educação enquanto aspecto socioeconômico, ainda que não seja exaustivo para compreender a realidade do Centro enquanto território negro. 


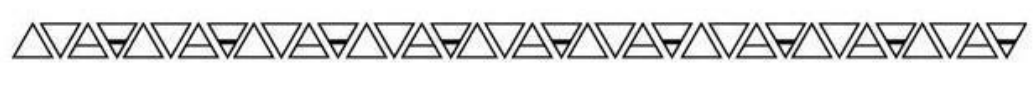

Desde 2008 o governo do estado de Santa Catarina fechou seis escolas em Florianópolis. Problemas estruturais nos prédios causados pela falta de manutenção, o baixo número de matrículas e alta evasão foram as causas que justificaram encerrar as atividades das unidades escolares, tendo como objetivo corte de gastos (GONÇALVES, 2015).

Esses fechamentos foram notados em bairros com uma sobrerrepresentação de pessoas negras, incluindo escolas que atendiam majoritariamente territórios negros, como a Coloninha e o Maciço do Morro da Cruz. A Coloninha, onde 19\% da população se declara negra, é conhecido bairro da parte continental do município e abriga elementos importantes da cultura negra na cidade, como a escola de samba homônima. Neste bairro localizava-se a Escola de Educação Básica Otília Cruz, que foi fechada em 2007. A partir de então, a comunidade ocupou o espaço e passou a oferecer oficinas de dança, futebol, corte e costura, computação e música, além de manter uma biblioteca. Em 2011, o espaço foi municipalizado e, em setembro de 2014, se tornou uma creche, outra demanda da comunidade.

A Escola de Educação Básica Dayse Werner Salles, fechada em 2014, fica no bairro Capoeiras, também na parte continental do município, onde $15 \%$ da população se declara negra. No fim de 2017, o governo do Estado transferiu a área à Universidade do Estado de Santa Catarina, que apresentou uma proposta de reconstrução da escola, já aprovada em audiência pública. A nova escola, que oferecerá exclusivamente ensino fundamental e contará com um ginásio poliesportivo que será compartilhado entre o curso de educação física da universidade, deve ser entregue ainda em 2020.

No Centro, além da Escola de Educação Básica Antonieta de Barros, outras três escolas foram descontinuadas. A Escola de Educação Básica Silveira de Souza atendia 224 estudantes e foi fechada em 2009. A partir de 2013, recebe alunos do único núcleo de EJA matutino do município. Em 2014, a escola de música da prefeitura também passou a funcionar lá. Já a Escola de Educação Básica Celso Ramos atendia 300 estudantes, majoritariamente oriundos do Maciço do Morro da Cruz, quando foi fechada, em 2010. A intenção do governo do estado era doar a área para a Assembleia Legislativa, que gostaria de ampliar seu estacionamento. As associações comunitárias do entorno pressionaram o estado a doar a escola para a Prefeitura de Florianópolis, que construiu uma creche (GONÇALVES, 2015). Mais recentemente, em 2019, a Escola de 
Educação Básica Lauro Müller foi fechada, apesar de protestos da comunidade escolar. As/os 255 estudantes, muitos moradores do Centro, outros de bairros mais distantes, mas cujos pais ou responsáveis trabalhavam no Centro, foram comunicados do fechamento da escola com menos de dois meses para o fim do ano letivo. As famílias poderiam optar por matricular seus filhos no Instituto Estadual de Educação (que atende cerca de 6 mil estudantes) ou na Escola de Educação Básica Henrique Stodieck (que também está no relatório do Ministério Público de Santa Catarina que solicitou a reforma da Lauro Müller). No momento do fechamento da escola, cujo prédio é vizinho da Igreja da Irmandade Negra de Nossa Senhora do Rosário e São Benedito, não haviam planos de reforma ou ocupação para o edifício.

A Escola Antonieta de Barros foi fechada em 2008 e desde então a responsabilidade sobre a escola saiu da Secretaria de Estado da Educação para a Secretaria de Estado da Administração. Essa transferência ilustra o apagamento da função social da construção histórica, visto que a Secretaria da Administração a percebe e realiza sua gestão como um prédio público do estado como tanto outros. Esse é um fato importante quando pensamos que enquanto unidade de ensino a escola é um marcador socioeconômico do Centro enquanto território negro.

Apesar de Santa Catarina ser um estado com o Índice de Desenvolvimento da Educação Básica superior à média nacional, no município de Florianópolis essa excelência se materializa no fechamento de escolas em territórios negros, que se transformam em lugares do não direito. Silva afirma que

o lugar urbano e social que o negro ocupa não é o mesmo do branco. A separação é evidente, embora haja um permanente controle para que possa parecer que todos têm o mesmo tipo de acesso a algo de interesse (SILVA, 2006, p. 70).

Essa hierarquia racial que inferioriza a população negra demonstra que não é somente a classe que demarca as possibilidades que cada grupo pode alcançar, onde estatisticamente os brancos possuem vantagens sobre os negros, ainda que não as mesmas que seus pares ricos.

\section{MARCADOR POLÍTICO}


Considerando a história da educação da população negra no Brasil, a exclusão deste grupo dos espaços formais de formação e também a resistência organizada dos mesmos, percebemos porque o direito à educação sempre foi bandeira do Movimento Negro no país em suas diversas expressões. A exclusão, que vai desde a proibição legal instituída no século XIX e permanece nos dias atuais com as práticas escolares que dificultam ou interrompem as trajetórias das crianças e adolescentes negros/as (como o fechamento de escolas), é encontrada com resistências durante o mesmo período, como o pedido de uma comissão de trabalhadores libertos pelo apoio do então jornalista Rui Barbosa na denúncia do não cumprimento da criação do fundo de emancipação de 1871, especialmente no tocante à instrução de seus filhos e, atualmente, as leis 10.639/03 e 11.645/08 (obrigam o ensino de história do continente africano, da cultura afrobrasileira e indígena) e a lei 12.711/12 (também conhecida como lei de cotas), conquistas do movimento negro brasileiro.

Ao ler a matéria intitulada "Queremos estudar", assinada por Haroldo Costa na seção Tribuna Estudantil do jornal Quilombo, informativo do Teatro Experimental do Negro $^{2}$, encontro um sentimento presente em 1948 que permanece 72 anos depois: “[...] Nos dias de hoje a pressão contra a educação do negro afrouxou consideravelmente, mas convenhamos que ainda está muito longe do ideal" (COSTA, 2003 [1948] apud ROMÃO, 2005, p. 127). Mesmo com novas demandas, a luta pelo direito à educação para a população negra no país, ainda que garantido pela Constituição, continua atual e necessária.

Aponto também o aspecto político do nome da escola, visto que a toponímia traz consigo mais do que uma homenagem à professora, poeta e deputada, ao denotar reconhecimento ao legado de Antonieta de Barros na luta pela educação, pelos direitos das mulheres e da população negra. A escola, ao ser reconhecida como marcador cultural, socioeconômico, político da luta antirracista em Florianópolis, também materializa a condição histórica da reivindicação do povo brasileiro, em especial do povo negro neste caso, pelo direito à vida com dignidade, onde nossos direitos fundamentais como acesso à educação pública e de qualidade sejam garantidos.

\footnotetext{
2 O Teatro Experimental do Negro foi fundado em 1944, no Rio de Janeiro, por Abdias do Nascimento. Para mais, consultar Romão (2005).
} 


\section{CONFLITO DE INTERESSES E MEDIAÇÃO DO ESTADO}

Em 2019, o professor Lino Peres, atualmente vereador na Câmara Municipal de Florianópolis, a partir de demanda do movimento negro articulada por sua assessoria em Direitos Humanos, instigou a Deputada Estadual Luciane Carminatti à promover uma audiência pública para debater o futuro do prédio da Escola Antonieta de Barros. Na ocasião, foi apresentada a proposta do movimento negro local: transformar o prédio no Centro de Memória e Cultura Negra de Santa Catarina Antonieta de Barros, preservando sua função social enquanto espaço formativo e público atingido.

$\mathrm{Na}$ audiência estavam presentes militantes do movimento negro, professoras/es e ativistas na defesa da educação pública e representantes da Câmara de Dirigentes Lojistas de Florianópolis, demonstrando os diversos interesses sobre o prédio. Em minha dissertação, tratei acerca da gentrificação de territórios negros a partir do Mercado Público de Florianópolis, outro marcador do Centro enquanto território negro. A gentrificação tem como ideia de valorização e requalificação de espaços públicos populares a partir da lógica consumista, a partir da eugenização de ambientes, onde, por exemplo, botecos são substituídos por estabelecimentos para pessoas com maior poder aquisitivo, removendo os aspectos culturais e simbólicos desses espaços para a obtenção de ganho monetário. A postura eugenista vista aqui associa "desenvolvimento" a embranquecimento que, quando não pode ser biológico, deve ser cultural. A área da cidade em que a escola está localizada vem passando por um processo de gentrificação acelerado. Nas noites de sexta e sábado, especialmente, é perceptível uma linha de classe e raça que separa os frequentadores da Rua Victor Meirelles. A falta de espaços de lazer, os preços praticados nos estabelecimentos e seus tamanhos reduzidos até mesmo para seu público-alvo (jovens universitários majoritariamente brancos e de classe média), originou o Fluxo do Mada. O movimento espontâneo de jovens, oriundos especialmente do Maciço do Morro da Cruz, na rua em frente aos novos bares é constantemente encerrado pela Polícia Militar ao fim do funcionamento dos estabelecidos, inclusive durante o Carnaval, com o uso de cassetetes e bombas de efeito moral. A mensagem é clara: as ruas só podem ser usadas à serviço do capital. Rodrigo Corrêa Diniz Peixoto e Jakson Silva da Silva apontam que esse processo de 
gentrificação embranquecedora ocorre em diversas cidades do país nas quais o espaço popular

não é valorizado, não é considerado como algo que pode ser melhorado, em termos de infraestrutura e de serviços, para permanecer enquanto espaço popular mesmo. A ideia que domina os projetos é a de substituir o uso popular desses espaços por usos capitalizados (PEIXOTO; SILVA, 2016, pg. 568).

Os/as lojistas, por sua vez, tem interesse na gentrificação deste espaço, pela valorização de seus empreendimentos e remoção de pessoas indesejadas. A mobilidade das pessoas pelo Centro, território em disputa, só é possível se elas seguirem uma série de regras e ordens que existem para controlar nossos corpos. O biopoder funciona a partir dessas práticas e formas sociais de controle de cada um de nós e é posto em prática à força, muitas vezes pela forma que as instituições do Estado e as propriedades da sociedade burguesa estão distribuídas e se comportam no espaço (MONDARDO, 2009). A presença e postura dos aparelhos coercitivos de segurança pública tão distantes entre corpos-territórios negros/pobres, onde executam realizam "abordagens" e "operações”, e corpos-territórios brancos/ricos onde garantem a segurança, é um exemplo da articulação do controle dos corpos na ordem espacial burguesa.

O governador de Santa Catarina, em seu poder frente a ordenação espacial a partir dos bens que possui, doou a escola para a Universidade do Estado de Santa Catarina (UDESC) poucas semanas depois da audiência pública, no dia 26 de dezembro. A lei 17.837, que efetiva a doação, diz em seu segundo artigo que "A doação de que trata esta Lei tem por finalidade a execução de atividades educacionais e culturais pela UDESC, voltadas à comunidade, à qualificação e formação de professores e à criação de um centro de memória e preservação da cultura negra". Apesar da aparente mediação de intenções, a imprensa local reporta os interesses da UDESC: "O espaço será usado para projetos de qualificação e formação de recursos humanos, além de inovação e economia criativa", indicando uma continuidade nas atividades realizadas pela UDESC no prédio vizinho à escola, já administrado pela universidade, onde abriga o Museu da Escola Catarinense, aliada à start-ups e outras iniciativas da economia criativa visando o desenvolvimento e produção de bens e serviços focados no comércio.

Apesar do texto da lei deixar explícito a proibição de desvio a finalidade da doação sob pena da reversão da mesma, não aponta que centralidade do prédio deve ser 
o Centro. É importante lembrar que historicamente a população negra é tratada como anexo à espaços de memória oficial, especialmente no Sul do Brasil, onde sua presença é constantemente invisibilizada. O próprio Museu da Escola Catarinense, também gerido pela Udesc, é um exemplo desse tratamento, onde toda a experiência da população negra nas escolas de Santa Catarina é resumida à uma sala com a importante mobília utilizada pela professora Antonieta de Barros e seu busto, ambos patrimônios da história do país, considerando-se a importância da deputada. Não há menção à experiência indígena ou de outros grupos racializados.

As instituições são muito importantes nesse controle dos corpos-territórios, pois são partes do Estado pensadas para reprimir as tentativas de revoltas contra a ordem espacial imposta como "verdadeira". Nesse sentido, as escolas, universidades, o sistema de saúde, de segurança pública, e entre outros, como museus, cumprem um papel na manutenção dessa ordem espacial burguesa. A proposta do Estado - mediada a partir de um dos seus espaços de legitimação de saber, a universidade - ainda não foi apresentada em sua totalidade, mas é improvável que a mesma considere a dívida histórica que o mesmo possui com os povos racializados de Santa Catarina. Essa afirmação baseia nas práticas da instituição que, mesmo com obrigação legal, não implementa de forma efetivas políticas de permanência para estudantes cotistas ou fiscaliza os componentes curriculares de seus cursos visando a implantação das leis 10.639/03 e 11.645/08 (PASSOS; NOGUEIRA, 2019). Como tudo indica, não há dúvidas que o único espaço público destinado à cultura negra na capital do estado será dentro de um prédio multifuncional administrado pelo estado, mas sim de como a materialização do centro de memória e preservação da cultura negra acontecerá.

\section{CONSIDERAÇÕES FINAIS}

Tendo em vista que os territórios negros expressões espaciais que geografam as relações raciais, o apagamento de um deles reflete as dinâmicas de poder presentes em uma sociedade que impede a livre existência da multirracialidade em seu seio. O projeto de cidade burguesa posto em prática em Florianópolis invisibiliza a população negra ao higienizar e gentrificar seus territórios a partir de políticas públicas desracializadas que atingem essa população. 
Os territórios que se constituem enquanto resistência ao poder hegemônico que constitui o sistema colonial, capitalista, racista, sexista, capacitista entre outras estruturas de hierarquização de corpos, se apresentam como fatos espaciais que podem mostrar outras formas de organização social e econômica, além de se constituírem como espaços de resistência identitária frente ao sistema dominante.

Sendo as relações raciais essencialmente relações de poder centralizadas na hierarquização racial que organiza o mundo capitalista, as relações de poder entre os indivíduos se materializam nas relações sociais que se dão fundamentalmente através da política, meio pelo qual o Estado e as classes dominantes impõem suas formas de organização dos corpos e assim dos arranjos do espaço. Assim, ainda que se altere as formas de organização do espaço, sem a ruptura com as formas de controle dos corpos, as estruturas continuarão reproduzindo o sistema capitalista e todas as suas formas de opressão.

Considerando que o poder não é binário, e sim multidimensional e interescalar, são diversas as disputas por um mesmo corpo-território. Estes mecanismos de reprodução das desigualdades raciais no espaço são legitimados também por discursos acadêmicos, como observado a época do movimento sanitarista no Brasil. As muitas subjetividades envolvidas na produção do conhecimento são lidas, recebidas e interpretadas de forma muito singular por quem ocupa a posição de pesquisadora. Enquanto uma geógrafa negra, florianopolitana e militante do movimento negro, me parece fundamental reafirmar que o discurso hegemônico da Geografia acadêmica, especialmente aquele construído baseado na perspectiva materialista histórica, contribui no controle e apagamento de corpos-territórios negros ao não considerar o papel da raça na formação sócio histórica e sócio espacial do mundo, especialmente do Brasil. Dessa maneira, ao empregar a raça como conceito analítico opta-se por não ignorar um elemento estruturante da sociedade brasileira em sua constituição e reprodução.

É a partir da raça que se centralizam os elementos presentes na defesa da manutenção da função social da Escola Antonieta de Barros a partir do reconhecimento do prédio enquanto um dos marcadores do Centro enquanto território negro. Com isso, demonstra-se a importância de reconhecer e fortalecer os territórios negros de forma generalizada, visto que eles materializam acúmulos históricos da luta antirracista e da resistência do povo brasileiro frente ao processo de construção de um falso mito de uma 
democracia racial, que naturaliza um controle de corpo-territórios que se utiliza de ferramentas genocidas para a manutenção da hierarquização racial e de classe no país.

Ainda que o racismo se utilize das estruturas do Estado ao mesmo tempo que as constituem (organização referenciada como racismo estrutural), no último censo realizado pelo IBGE, em 2010, negros e negras voltaram a constituir oficialmente a maioria do contingente populacional brasileiro, apesar da desaceleração do crescimento demográfico. Esse aumento da população negra combinado a redução da taxa de crescimento populacional também é observado em Florianópolis e aponta que parte da população brasileira mudou sua autodeclaração racial. O crescimento no sentimento de pertencimento racial, fomentado pelo Movimento Negro, seja pelo trabalho de base ou pela luta institucionalizada por políticas de ações afirmativas indica uma resistência organizada e seus reflexos na sociedade brasileira, que se compreende cada vez mais como negra. Frente a isso, espero que da mesma forma cada vez mais o Brasil se reconheça e seja reconhecido enquanto o território negro que é, reparando esta população e os demais grupos racializados que o habitam que, ainda que sejam maioria do contingente populacional, batalham para viverem a partir de suas cosmovisões de forma digna e com amplo acesso à direitos. A luta antirracista e contra todas as formas de opressão a serviço do capitalismo é travada em todos os aspectos da vida humana, nas cidades, na academia, em nossos corpos. Cientes de que não há neutralidade neste embate, cabe a nós, especialmente aquelas/es que ocupam espaços de poder, enfrentarmos as desigualdades na garantia pela equidade.

\section{REFERÊNCIAS BIBLIOGRÁFICAS}

ALAFÁIA. Na gira da rima. Notas do encontro realizado no dia 11 de outubro de 2017. Florianópolis.

AREND, Silvia Maria Fávero. Avançando pela encosta: condições de moradia dos pobres urbanos na era Vargas. Esboços, Florianópolis, v. 12, n. 14, p.133-148, set. 2005. Disponível em: https://periodicos.ufsc.br/index.php/esbocos/article/view/173/9938. Acesso em: 17 maio 2019.

BENEDITO, Vera Lúcia. Cor e territórios na cartografia das desigualdades urbanas. In: OLIVEIRA, Reinaldo José de (Org.). A cidade e o negro no Brasil: Cidadania e território. São Paulo: Ed. Alameda, 2013. p. 95-127. 
CARDOSO, Vitor Hugo Bastos; MAMIGONIAN, Beatriz Gallotti. Tráfico de escravos e a presença africana na Ilha de Santa Catarina. In: MAMIGONIAN, Beatriz Gallotti; VIDAL, Josiane Zimmermann (Org.). História diversa: africanos e afrodescendentes na Ilha de Santa Catarina. Florianópolis: Ed. da UFSC, 2013. p. 17-42.

CIRQUEIRA, Diogo Marçal. As inscrições da racialidade no pensamento geográfico (1890 1930). 2015. Tese (Doutorado) - Curso de Geografia, Universidade Federal Fluminense, Niterói, 2015.

FLORIANÓPOLIS. Projeto do Maciço do Morro da Cruz. Florianópolis: Secretaria Municipal de Infraestrutura. $2018 . \quad$ Disponível em: http://www.pmf.sc.gov.br/entidades/infraestrutura/index.php?cms=projeto+macico+do+morro+ da+cruz\&menu=7\&submenuid=303 >. Acesso em: 17 maio 2017.

GARCIA, Antonia dos Santos. Desigualdades raciais e segregação urbana em antigas capitais: Salvador, cidade D'Oxum, Rio de Janeiro, cidade de Ogum. Rio de Janeiro: Garamond, 2012.

GONÇALVES, Michael. Cinco escolas estaduais foram fechadas na Grande Florianópolis nos últimos sete anos. Hora de Santa Catarina. Florianópolis. 28 ago. 2015. Disponível em: $<$ https://www.nsctotal.com.br/noticias/cinco-escolas-estaduais-foram-fechadas-na-grandeflorianopolis-nos-ultimos-sete-anos >. Acesso em: 09 maio 2017.

MASSEY, Doreen. Um sentido global do lugar. In: ARANTES, Antonio A. O espaço da diferença. Campinas: Papirus, 2000, p. 176-185.

MINAYO, Maria Cecília de S. Violência social sob a perspectiva da saúde pública. Cad. Saúde Pública, Rio de Janeiro, v. 10, supl. 1, p. S7-S18, 1994. Disponível em: < https://www.scielo.br/scielo.php?script=sci_arttext\&pid=S0102-

311X1994000500002\&lng=en\&nrm=iso>. Acesso em 18 Mai 2015.

MONDARDO, Marcos Leandro. O Corpo enquanto "primeiro" território de dominação: $O$ biopoder e a sociedade de controle. Biblioteca On-line de Ciências da Comunicação, 2009. Disponível em: http://www.bocc.ubi.pt/pag/mondardo-marcos-o-corpo.pdf

MORTARI, Claudia; DEBORTOLI, Gabrielli. João Rebolo e Domingas da Costa: Identidades africanas construídas e ressignificadas na diáspora (Desterro, século XIX). In: ENCONTRO ESTADUAL DE HISTÓRIA DA ANPUH/SC, 15., 2014, Florianópolis. Anais [...] Florianópolis: Anpuh, 2014. p. 01 - 15. Disponível em: < http://www.encontro2014.sc.anpuh.org/resources/anais/31/1405898767_ARQUIVO_ArtigoAnp uh.pdf>. Acesso em: 17 mar. 2019.

NOGUEIRA, Azânia Mahin Romão. Territórios negros em Florianópolis. 2018. 137 p. Dissertação (Mestrado) - Universidade Federal de Santa Catarina, Centro de Filosofia e Ciências Humanas, Programa de Pós-Graduação em Geografia, Florianópolis, 2018. Disponível em: 〈http://www.bu.ufsc.br/teses/PGCN0690-D.pdf〉

OLIVEIRA, Denílson Araújo. Territorialidades do hip-hop: desvelando tensões raciais na reprodução dos espaços urbanos. In: Renato Emerson dos Santos. (Org.). Questões Urbanas e Racismo. Petrópolis, RJ e Brasília, DF: DP et Alli e ABPN, 2012, v. 1, p. 244-275. 
PASSOS, Joana Célia dos; NOGUEIRA, Azânia Mahin Romão. A educação das relações raciais no currículo: as Licenciaturas em Geografia em Santa Catarina. Roteiro, v. 44, n. 1, p. 5, 2019. Disponível em: https://portalperiodicos.unoesc.edu.br/roteiro/article/view/17246

PEIXOTO, Rodrigo Corrêa Diniz; SILVA, Jakson Silva da. Segregação racial na orla de Belém: os portos públicos da Estrada Nova e o Ver-o-Peso. Boletim do Museu Paraense Emílio Goeldi. Ciências Humanas, Belém, v. 11, n. 3, p. 563-579, Dec. 2016.

RATTS, Alex. As etnias e os outros: as espacialidades dos encontros/confrontos. Espaço e Cultura, Rio de Janeiro: UERJ, N. 17-18, jan/dez, 2004, pp. 77.88. Disponível em: $\langle$ https://www.e-publicacoes.uerj.br/index.php/espacoecultura/article/view/7855/5683>. Acesso em: 10 out. 2017

RATTS, Alex. Os lugares da gente negra: temas geográficos no pensamento de Beatriz Nascimento e Lélia Gonzalez. In: SANTOS, Renato Emerson dos (Org.). Questões urbanas e racismo. Petrópolis: Dp Et Alii, 2012. p. 216-243. (Coleção Negras e Negros: Pesquisas e Debates).

RITMO, poesia e resistência: as batalhas de rap em Florianópolis. Roteiro: Rafael Thomé. Florianópolis: Diário Catarinense, 2017. (8 min.), son., color. Série Nós 97. Disponível em: $<$ http://www.clicrbs.com.br/sites/swf/dc_nos_97_rapfloripa/index.html>. Acesso em: 5 set. 2017.

ROMÃO, Jeruse. Educação, instrução e alfabetização no Teatro Experimental do Negro. In: ROMÃO, Jeruse (Org.). História da Educação do Negro e outras histórias. Brasília: Ministério da Educação, 2005. p. 117-138. (Coleção Educação para Todos).

SANTOS, Milton. O espaço do cidadão. São Paulo: Nobel, 1987.

SILVA, Maria Nilza da. Nem para todos é a cidade: Segregação urbana e racial em São Paulo. Brasília: Fundação Cultural Palmares, 2006. 232 p.

SODRÉ, Muniz. O terreiro e a cidade: A forma social negro-brasileira. Petrópolis: Vozes, 1988. $165 \mathrm{p}$.

SOUZA, Angela Maria de. A caminhada é longa e o chão tá liso! O Movimento Hip Hop em Florianópolis e Lisboa. 1. ed. São Leopoldo: Trajetos Editorial, 2016. 206p.

SOUZA, Angela Maria de. O movimento do rap em Florianópolis: a Ilha da Magia é só da ponte pra lá! Dissertação de Mestrado, PPGAS. Florianópolis: UFSC, 1998.

SOUZA, Marcelo Lopes de. O território: sobre espaço e poder, autonomia e desenvolvimento. In: CASTRO, Iná Elias de; GOMES; Paulo César da Costa; CORRÊA, Roberto Lobato. Geografia: conceitos e temas. 14 ed. Rio de Janeiro: Bertrand Brasil, 2011, p. 77-116.

VEIGA, Eliane Veras da. Florianópolis: memória urbana. 2. ed. rev. ampl. Florianópolis: Fundação Franklin Cascaes, 2008. 415 p.

Recebido em: 22/09/2020

Aceito em: $30 / 10 / 2020$ 